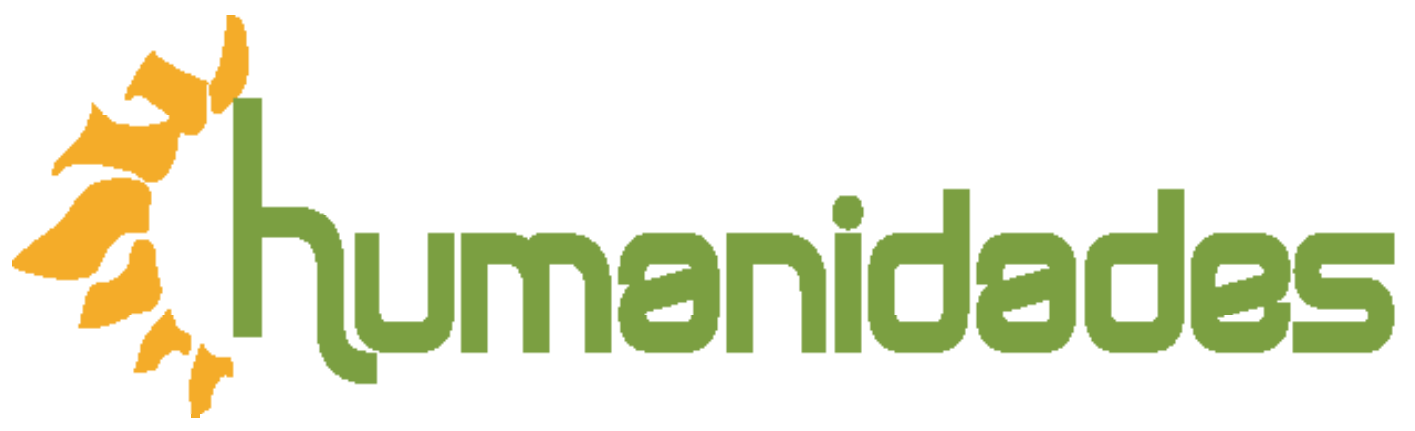

Revista de la Escuela de Estudios Generales, Universidad de Costa Rica

Julio-diciembre, 2019 •Volumen 9, número 2 • EISSN 2215-3934 • pp. 1-32

Recibido: 07-Enero-2019 Aceptado: 22-Enero-2019

\title{
"Bolivia es una sola montaña". Apuntes sobre los discursos y las representaciones en torno a la nación elaborados por el gobierno del MAS durante el 2009
}

DOI: https://doi.org/10.15517/h.v9i2.37125

\section{María Laura Amorebieta y Vera}

Licenciada en Sociología y doctoranda en Historia

Universidad Nacional de La Plata, Instituto de Investigaciones en Humanidades y

Ciencias Sociales, Consejo Nacional de Investigaciones Científicas y

Técnicas, Argentina

Correo electrónico: lamorebieta@fahce.unlp.edu.ar / lauraamorebieta@gmail.com

Todos los derechos reservados. Universidad de Costa Rica. Esta revista se encuentra licencida con Creative Commons. Reconocimiento-NoComercial-SinObraDerivada 3.0 Costa Rica. Correo electrónico: humanidades@ucr.ac.cr/ Sitio web: http: //revistas.ucr.ac.cr/index.php/humanidades 


\section{"Bolivia es una sola montaña". Apuntes sobre los discursos y las representaciones en torno a la nación elaborados por el gobierno del MAS durante el 2009}

\section{Resumen}

Hacia mediados de los años 30 se consolidaba en Bolivia la narración del país de contactos como doctrina geopolítica formal, la cual se asentó sobre las ideas elaboradas por los pensadores del territorio de principios del siglo XX. Entre estos últimos, se encontraba Jaime Mendoza Gonzáles, quien sostenía que los Andes constituían “el sustrato básico" de la nacionalidad boliviana. Este escrito tiene como objetivo volver sobre las raíces de este dispositivo discursivo, así como analizar su impacto y persistencia en la retórica del gobierno del MAS. Puntualmente, se propone observar de qué manera las nociones que sirvieron de fundamento a dicha narrativa presionaron sobre la memoria histórica trazada por el gobierno del MAS durante la inauguración del "Bicentenario de los Pueblos" en el 2009, dando lugar a una idea de Bolivia que pareciera tropezar con la búsqueda oficial por extender e integrar la nación en clave plurinacional.

\section{'Bolivia es una sola montaña.' Notes on the Discourses and Representations of Nation Deployed by MAS Government During 2009}

\begin{abstract}
Towards the middle of the 1930s, the narrative of 'país de contactos' consolidated in Bolivia as formal geopolitical doctrine, which relied on the ideas of the nineteenth-century thinkers of territory. Among them was Jaime Mendoza Gonzáles, who claimed that the Andes constituted 'the basis substrate' of the Bolivian nationality. The main objective of this paper is to deepen the understanding and clarify elements contained in this discursive device as well as analyze its persistence and impact on the rhetoric of MAS government. Specifically, this work will observe in which way the notions that served as the basis of the narrative of 'país de contactos' pressed on the historical memory projected by MAS government during the inauguration of 'Bicentenario de los Pueblos' in 2009, giving rise to an idea of Bolivia which would seem to stumble toward the official intention of spreading and integrating the nation as a plurinational one.
\end{abstract}

Palabras clave:

Bolivia, gobierno, nacionalismo, memoria colectiva, discurso

Keywords:

Bolivia, government, nationalism, cultural memory, speeches 


\section{Introducción}

Hacia el año 2014 la Vicepresidencia del Estado Plurinacional de Bolivia comenzaba a dar forma a uno de los proyectos editoriales más ambiciosos de la historia del país: la Biblioteca del Bicentenario de Bolivia ${ }^{1}$. En el marco del denominado "Bicentenario de los pueblos 2009-2025", el gobierno del MAS -Movimiento al Socialismo- se proponía, entonces, lanzar por etapas, doscientas obras consideradas "fundamentales para la comprensión del pasado y presente del país" cuya lectura permitiría "a los bolivianos verse a sí mismos y figurar, de ese modo, el futuro de Bolivia” (Biblioteca del Bicentenario de Bolivia, s.f., párr. 2). Entre ellas, el Comité Editorial encargado de la selección incluiría en una misma edición El factor geográfico en la nacionalidad boliviana (1925) y El Macizo Boliviano (1935), dos libros escritos por Jaime Mendoza Gonzáles (1874-1939), un médico, intelectual, poeta y político sucreño que contribuiría a forjar la idea de que los Andes constituían "el sustrato básico" de la nacionalidad boliviana.

Siguiendo a Perrier Bruslé (2015), esta caracterización de Bolivia era la que se hallaba detrás de la narración del país de contactos consolidada como doctrina geopolítica formal hacia mediados de la década del 30, por el entonces canciller de Bolivia, Luis Fernando Guachalla. Para ello, el canciller retomaría a los pensadores del territorio de principios del siglo $\mathrm{XX}$, entre los que se encontraba Mendoza, el cual sostenía que el enclaustramiento y la pérdida de la mitad del territorio desde la independencia hasta la guerra del Chaco habían hecho de Bolivia un "país tambaleante". En este sentido, Guachalla consideraba que su existencia solo podría asegurarse mediante la inserción del altiplano en el continente como lugar estratégico -o "heartland"- capaz de arbitrar los intercambios económicos y la comunicación entre sus vecinos, así como contribuir al equilibrio continental como espacio neutro entre las dos potencias de Sudamérica, Brasil y Argentina. De modo que este dispositivo discursivo surgía, en aquel entonces, con el propósito de encontrarle "utilidad" a Bolivia para asegurar y justificar su permanencia y autonomía. 
Abandonada a mediados del siglo XX cuando se priorizó la integración nacional, Bruslé (2015) explica que esta narrativa recuperaría su vigor durante las décadas neoliberales de los ochenta y noventa, ligándose, en esta ocasión, a la apertura de fronteras y a la conformación de bloques económicos de libre comercio en un mundo globalizado. Según la autora, si bien la crisis del modelo neoliberal, la elección de Evo Morales y la puesta en marcha de un "proceso de cambio" a partir de 2005 deberían "haber cuestionado este modelo", el presidente retomó "en grandes líneas la geopolítica formal tradicional boli-viana dentro de la cual la narración del país de contactos es central” (p. 104).

Ahora bien, a diferencia de sus orígenes, cuando las ambiciones procedentes de los países vecinos pesaban sobre el territorio boliviano, la reapropiación de esta narrativa por parte de Morales situaría la globalización neoliberal como la amenaza que ahora acechaba al Estado y la soberanía nacional ${ }^{2}$. En este contexto, el presidente del Estado Plurinacional de Bolivia reivindicaba a los Andes en tanto cuna de una América precolonial poderosa, proclamando al altiplano boliviano como el centro simbólico y geopolítico de una nueva articulaciónn regional sudamericana, por ser allí donde se habrían arraigado desde siempre las principales fuerzas de resistencia a los poderes hegemónicos.

Este escrito tiene como objetivo volver sobre las raíces de la narración del país de contactos surgida en los años treinta, así como analizar su impacto y persistencia en la retórica del gobierno del MAS. Puntualmente, se propone observar de qué manera las nociones sobre las cuales se asentó este dispositivo discursivo presionaron sobre la memoria histórica trazada por el gobierno central durante la inauguración del "Bicentenario de los Pueblos" en el 2009, dando lugar a una idea de Bolivia que pareciera tropezar con la búsqueda oficial por extender e integrar la nación en clave plurinacional.

En vista de ello, el trabajo se estructura en dos apartados centrales: en la primera parte se hace especial hincapié en el modo en que la sociedad, la historia y el territorio bolivianos aparecen formulados en las obras de Mendoza, reeditadas en el 2016 por el gobierno del MAS, las cuales -con excepción del trabajo de Brusléraramente han sido ubicadas dentro del conjunto de influencias del pensamiento del MAS. 
Luego, se analiza de qué modo estas ideas son recuperadas en los discursos presidenciales y vicepresidenciales pronunciados en el marco de tres efemérides conmemoradas a lo largo del 2009: el bicentenario de la Revolución de Chuquisaca ( 25 de mayo), el bicentenario de la Primera Junta Tuitiva de Gobierno (16 de julio) y el $184^{\circ}$ aniversario del Día de la Independencia (6 de agosto) $)^{3}$. Finalmente, en las conclusiones se aborda el dilema de la reconstrucción de la identidad nacional boliviana, así como el desafío que enfrentaría el gobierno del MAS al momento de intentar una auténtica construcción hegemónica a nivel nacional.

\section{Jaime Mendoza y "el gran Macizo Andino"}

Las décadas del 20 y 30 traerían en Bolivia una serie de cambios paulatinos, aunque significativos, que pondrían en jaque el statu quo oligárquico liberal. La aparición del multipartidismo en el sistema político local, el debilitamiento de la ideología liberal con su fuerte impronta racista, la conformación de un movimiento obrero fuerte, el surgimiento de una izquierda radical que exclamaba "tierras al indio, minas al estado", la creciente movilización indígena expresada en levantamientos y rebeliones, así como la derrota en la Guerra del Chaco y la emergencia del nacionalismo revolucionario parecían sentar las condiciones de posibilidad para intentar (re)construir las bases de la identidad nacional, integrar al país y redimir al "indio".

En este contexto de crisis fue que tuvo lugar la publicación de El factor geográfico... y El Macizo..., en las cuales Mendoza, apelando a las tesis del determinismo geográfico finisecular ${ }^{4}$ pero también a nociones culturales y espirituales de la cosmovisión indígena de base andina ${ }^{5}$, sistematizó su doctrina geopolítica de la reintegración territorial y social'. Allí, el pensador sucreño afirmaba que "lo que constituye el núcleo básico de la nacionalidad boliviana, geográficamente hablando, es el Macizo Boliviano" (Mendoza, 2016, p. 89), delineando así la premisa clave de su teoría, centrada en la idea de que la geografía de la altiplanicie había ejercido y continuaba ejerciendo una influencia "decisiva y profunda" sobre la historia y la sociedad boliviana. 
Como prueba de ello, Mendoza elaboró a lo largo de El factor... un recorrido histórico, caracterizado como "a la vez de regresión, de repetición y de renovación" que iniciaba en tiempos preincaicos con la civilización de Tihuanaco, indicando que:

fue la metrópoli de un potente Estado que hace más de 10 mil años floreció en el mundo (...). Así nos lo demuestran esas piedras labradas, que bien valen por una historia larguísima escrita por manos gigantescas. Esas piedras (...) son signos contundentes que nos están diciendo que, así como el Macizo Andino había sabido elevarse sobre la faz continental a tan enorme altura, merced a las fuerzas recónditas del globo, que allí reventaron con proporciones colosales, de igual suerte, una raza de hombres rudos, bajo el influjo de sus incontenibles energías, supo constituir en esas altitudes un foco de cultura humana extraordinario (...).

Y estos mismos monumentos nos están diciendo además otra cosa: que el medio en que actuaba esa raza fue parte, y no pequeña, para inducirla a realizar esos prodigios (...).

Hay que recordar a este propósito la admirable armonía que desde tiempos inmemoriales se ha producido entre ciertos medios y sus moradores. En la meseta del Irán (...) nació el gran Imperio Persa (...) en América, en la meseta del Anahuac (México), floreció también otra raza briosa (...). Y ahora, tratándose (...) del Macizo Boliviano, es muy natural deducir que allí también una raza bien dotada hubiese hallado condiciones propicias para su cultura y engrandecimiento. (Mendoza, 2016, pp. 69-70)

De modo que las grandes montañas habrían sido cuna de las más importantes civilizaciones. En el caso del Macizo Andino, su ímpetu y fortaleza favorecieron el surgimiento de la enigmática "Ciudad de Gigantes", considerada la cultura más antigua de la América preincaica, que -según rezan las leyendas andinas- habría sido construida en el curso de una sola noche por seres gigantes. Sin embargo, para Mendoza, fue aquel particular medio geográfico el que habría dado origen a una "raza de hombres" lo suficientemente fuertes como para construir las impactantes obras arquitectónicas que aún permanecen a orillas del lago Titicaca. 
"Pero, pasa Tihuanacu, y viene la noche", reanudaba el autor, señalando que un nuevo impulso civilizatorio, esto es, el surgimiento del Imperio Inca en el siglo XIII, tendría lugar no en Cuzco, sino sobre las mismas orillas en las que entonces se había levantado la cultura tihuanaco y en las cuales, insistía, ya se hallaba "la raza de los quechuas y los aymaras". Es que "el gran Macizo continuaba siendo el sustentáculo fundamental del nuevo imperio (...). El Titicaca continuaba siendo para ellos el lugar sagrado, donde se recogían llenos de unción y respeto" (Mendoza, 2016, p. 75).

La historia trazada por Mendoza -todavía impregnada de positivismo evolucionista, aunque acompañada de una reivindicación de la cosmovisión andina como el rol de la naturaleza o Pachamama y, por momentos, cierta concepción cíclica del tiempo o Pachakuti- ${ }^{8}$ proseguía con la llegada de los españoles al actual territorio boliviano y la organización de la Real Audiencia de Charcas, cuyo "primordial basamento" sería nuevamente el Macizo Andino, dando inicio a una nueva etapa "de evolución humana que debía durar cerca de 300 años", durante la cual -"no obstante la condición de territorio conquistado a que había ingresado el macizo"ocurrirían "los primeros gestos de rebeldía contra la Corona Hispana".

El eslabón andino central se erigía como el principal bastión de resistencia contra el imperio español no solo a finales del siglo XVIII, sino también durante las guerras de independencia. En efecto, "es de entre los rincones más recónditos de sus montañas" que salieron, recordaba Mendoza (2016) "los primeros gritos en favor de la libertad" y nuevamente el medio, "del que son hijos", favorecería a los insurgentes. "Él les da esa indomable resistencia con que abruman al enemigo poderoso" (pp. 73-74).

La derrota del ejército, entendida como "un fenómeno que lógicamente debía producirse", se vinculaba al hecho de que:

Los realistas (...) acabaron también por familiarizarse con la topografía del territorio que pisaban y, puesto que tenían muchos más recursos que los otros, supieron, diestramente, posesionarse de los mejores sitios (...). Esto es, los españoles volvieron en su favor las condiciones estratégicas del gran Macizo altoperuano. Y de esta suerte, cuando ya la guerra continental había concluido y la España había sido vencida desde Venezuela hasta la Argentina, todavía continuaba adherida al Alto Perú (Mendoza, 2016, p. 74) 
Ahora bien, sería la gesta de Sucre, bajo órdenes de Bolívar, junto al accionar “de los altoperuanos" los que condujeron a la liberación del Alto Perú. Así, la independencia no habría sido solamente obra de grandes figuras, esto es, los libertadores, sino que, para Mendoza, los altoperuanos, "aún antes de que Sucre se encarase con el ejército del realista Olañeta, destruyeron a este en Tumusla y solo entonces quedó el Alto Perú libre del yugo español” y decidido a "conducirse por sí mismo".

De esta manera, es posible identificar en su ensayo un punto de ruptura con la historiografía liberal decimonónica que, en un intento por forjar una identidad nacional que sirviera de soporte a los nuevos Estados, había postulado a los grandes héroes de la independencia como únicos agentes históricos. En el énfasis otorgado a "los altoperuanos" como núcleo original de la nación, es posible observar cómo también había calado en el autor - no sin contradicciones o puntos de conflicto, como veremos más adelante- un tipo de mirada y sensibilidad hacia el mundo popular que, en las primeras décadas del siglo XX en América Latina, se proponía legitimar los elementos subalternos y pregonar la potencia transformadora del pueblo:

¿quiénes fueron los creadores de la nacionalidad boliviana?

Dicen los unos que fue Bolívar. Otros afirman que fue Sucre. Para nosotros fueron los mismos altoperuanos (...).

Los verdaderos promotores de la idea de hacer sobre estas "breñas de los Andes", una república; los que imaginaron primitivamente esa entidad, y aun podemos decir los que la inventaron, no podían ser otros que los mismos hijos del país.

Y esa idea original, esa imaginación, esa invención fueron inspiradas a nuestro juicio en los hijos del país, por su propio medio, según dejamos dicho. Pero es el caso que, por mucha imaginación e inventiva que tuviesen los altoperuanos, se hallaban terriblemente embarazados para llevar a la práctica sus propósitos (...). Y fue entonces que los altoperuanos supieron valerse astutamente de Bolívar y Sucre (Mendoza, 2016, pp. 79-80) 
En efecto, el pensador sucreño especulaba con el hecho de quizás en la población altoperuana

quedaban aún partículas de la sangre pujante de los constructores del Tihuanacu. Y, sin duda alguna, había en ellos sangre del rudo habitante de la Altiplanicie, del aymara tenaz o del (...) quechua, más dulce, pero no menos resistente.

Y en ellas estaba también la sangre del español, de ese fiero soldado que apenas trasladado a estas montañas, sintió su extraño influjo y se rebeló contra su mismo rey (Mendoza, 2016, p. 83)

De modo que aquel particular medio geográfico -la altiplanicie con su aridez y sus lagunas- había sido el responsable de toda una genealogía de auténticos hombres fuertes -nativos y extranjeros-, cuyos atributos heredaron los patriotas -indígenas, mestizos y blancos- que ahora liberaban a la nación. El medio, entonces, había ido forjando las fuerzas colectivas que funcionaban como motor de la historia y garantizaban el progreso de la "nación".

Sin embargo, afirmaba Mendoza, Bolivia había nacido con un "defecto original" de naturaleza geográfica en la medida que "no ocupaba toda la meseta andina (...) y nacía despojada de casi todas las costas que le pertenecían por la Naturaleza". Respecto a las tierras bajas -la "Bolivia posterior" o "marginal”-, aquél afirmaba que "se hallaban tan lejos del eje nacional que más que la atracción de este debían sentir la de los Estados vecinos" y que "por grandes pérdidas territoriales que haya sufrido la República, ellas, por lo menos (...) no afectaban su misma vitalidad"9. Por lo que fue "la deformación de que ha sido víctima Bolivia por el occidente" la que habría conducido a que la unidad geográfica original, una vez establecida la República, se hallara rota, radicándose allí la causa de todos los males que desde entonces afectaban a un "pueblo [que] apenas nacido, parecía destinado por sus defectos orgánicos a una muerte inmediata"10. 
Ahora bien, ¿cómo explicar, entonces, su persistencia en el tiempo? Para ello, Mendoza volvería a insistir sobre el carácter central y constitutivo de la altiplanicie en tanto "gran plataforma de la República". En efecto, aseveraba:

Ella es el eje cerebro-medular del país. A ella convergen las mayores actividades de todas las tierras vecinas por un movimiento centrípeto común. Y de ella, por un movimiento centrífugo, se dirigen hacia las demás derivaciones del macizo las corrientes engendradoras de un nacionalismo evidente.

La meseta se impone a tal punto que hasta llega a suscitar las protestas de los demás pueblos del contorno. Así se explica el predominio de La Paz. Se dice que él es un predominio político. Nosotros creemos que es, ante todo, geográfico. Es una influencia fatal. Es la misma que debió ejercer Tihuanacu en los tiempos pretéritos. Es como la influencia macedónica en la Grecia o como lo que fue la de la meseta del Irán en Persia (...) siendo todo esto así, bien se comprende que, si hasta hoy supervive la nacionalidad boliviana, es porque en el Macizo Boliviano, y en especial sobre la gran meseta que lo integra, subsisten también los elementos generatrices que lo formaron (...). El factor geográfico ha seguido jugando en esto el rol principal. Ha triunfado el espíritu creado por él aun por sobre las contradicciones de la raza (Mendoza, 2016, pp. 89-90)

Más allá de las amputaciones y el enclaustramiento sufridos por Bolivia, su parte esencial, esto es, "sus verdaderas fuentes de vida y energía", sostenía Mendoza, no fueron afectadas, lo cual explicaría por qué incluso algo tan álgido como la pérdida de su litoral marítimo no condujo a la destrucción de su nacionalidad. En un claro intento por redefinir, integrar y resguardar la nación en el marco de una crisis política e ideológica interna -que incluía la eclosión del regionalismo cruceño- ${ }^{11}$, pero también, en un plano más general, la crisis de Europa como modelo civilizatorio tras la Gran Guerra, es posible observar en la argumentación trazada por el autor una convivencia ecléctica de huellas, metáforas e ideas propias del período de entresiglos -ligadas especialmente a una certidumbre en el progreso y el cientificismo- con otras nociones que, durante los años veinte -aquellos “años de tránsito, de ideas nómades" (Funes, 2006)-, empezaban a impugnar el paradigma positivista. 
Es así que en la investigación sociogeográfica e histórica elaborada por el médico y geógrafo -que entendía a la naturaleza como determinante del destino histórico de un pueblo- aparecían entremezclados rastros ideológicos y epistemológicos propios del positivismo con una sensibilidad y unos ingredientes que distinguían los ensayos de la época y servían de matiz a tal episteme como el telurismo, el vitalismo espiritualista, el misticismo $y$, como veremos a continuación, la preocupación por la "raza" indígena y su reconciliación con la nación.

Al preguntarse por la "unidad moral de la raza", Mendoza -oscilando entonces entre el paradigma racialista signado por categorías biológicas y una mirada que comenzaba a indagar en los aspectos culturales, históricos y sociales de la nación (Mailhe, 2005; Funes, 2006)- desestabilizaba los conceptos y las representaciones negativas todavía dominantes en torno al mundo indígena boliviano al afirmar:

Ahí tenemos a nuestro lado un ser que, no obstante las solemnes declaraciones de nuestra Constitución sobre los derechos del hombre, es un verdadero paria: el indio (...).

Hay quien lo considera el depositario de las energías de la raza (Franz Tamayo) y quien solo una "induración" maléfica, un ser refractario a la civilización (Gabriel René Moreno). ¿Dónde está la verdad? No lo sabemos. Nadie aún ha podido definir categóricamente esa extraña personalidad. No conocemos sus verdaderos instintos, su manera de ser afectiva, su capacidad intelectual, en una palabra: su índice psíquico total.

Pero, en fin, después de todo, hay ciertos hechos paradójicos que deben llamar nuestra atención respecto del papel que puede llenar el indio en Bolivia. Esa misma inmovilidad que tanto se condena en él, ¿no significa, bien mirada, un don de persistencia singular? Y la persistencia en una raza ¿no es una gran cualidad para sostener una nación?

Y en el espíritu gregario del indio (...) ¿no está aparejado otro don, el don de la disciplina tan útil para llevar a los pueblos al cumplimiento de grandes destinos?

Y esa misma rudeza, esa brutalidad (...) ¿no nos está diciendo que aún se trata de un terreno virgen donde una inteligente y tesonera educación podrá obtener en el futuro consecuencias incalculables? (Mendoza, 2016, pp. 110111) 
Para Mendoza, el "indio" - extraño, tosco e indescifrable, aunque susceptible de ser educado y disciplinado- no poseía ninguna incapacidad natural que actuara como freno para el surgimiento, desarrollo y modernización de la nación. En efecto, en este proceso, su barbarie habría sido un componente fundamental para el avance civilizatorio $^{12}$. Es así que el pensador-rompiendo, como vimos, con la cronología propia de las historias patrias- ubicaba el accionar de aquel en los orígenes de la gesta emancipadora, los cuales se remontaban a mucho antes de 1809:

$\mathrm{Y}$ en la guerra de nuestra Independencia tampoco hay que desconocer el papel del indio.

Porque no por la ignorancia y abyección en que se halla ha de creerse, cual dicen algunos, que no entra en su entendimiento el concepto de la patria.

Que el indio sabía bien lo que es la patria lo prueban los levantamientos de los Katari y de Túpac Amaru que ensangrentaron ambos Perús mucho antes de la insurrección de criollos y mestizos contra el régimen peninsular.

Pero en esta misma insurrección y guerra consiguiente la acción del indio fue también capital. Fue, más que nadie en ella, el "soldado desconocido", el héroe ananimó que no dejó ninguna huella de su memoria, pero sí los resultados positivos de su acción. (Mendoza, 2016, p. 113)

Entonces, más allá de su condición indigna e iletrada, el "indio" - esa raza fuerte y resistente fraguada en y por la montaña que, además, supo perpetuarse en sus descendientes, el mestizo ${ }^{14}$ había sido una pieza decididamente clave en la gesta emancipadora y, de igual modo, resultaba esencial para el presente y el futuro de Bolivia:

Él (...) está en la base misma de nuestra nacionalidad (...). Él resistió a la mita. Él fue la gran máquina de hacer dinero de que se valió el conquistador. $\mathrm{Su}$ papel en la industria, en el comercio, en las comunicaciones fue enorme (...) no obstante el desamparo en que lo tenemos, es todavía entre los elementos de trabajo que integran nuestro organismo lo más sólido y productivo para la economía nacional. La Bolivia minera sigue encontrando en él un caudal de energías inagotable. La agricultura está en sus manos. Nuestras comunicaciones, nuestro comercio, cuentan aún con él en máxima escala. Con su ayuda hemos construido nuestros más atrevidos ferrocarriles. Como soldado, sencillamente, no tiene igual. Y todas estas admirables cualidades las adquirió el indio por la acción de su propio medio. (Mendoza, 2016, pp. 112-113) 
Dos aspectos resultan interesantes de esta caracterización de la otredad indígena. En primer lugar, cabe detenernos en la -entonces usual- utilización del concepto "indio", el cual -como recuerda Funes- no funcionaba como "una denominación geográfica, ni étnica, ni clasista" sino que constituía "la denominación del vencido" (Funes, 2006), borrando las diversidades originarias y, en el caso de Mendoza, utilizándolo como equivalente a quechua y aymara. Si el "indio" se ubicaba en la base de la nacionalidad boliviana y el núcleo fundamental de esta se encontraba en el "gran Macizo Andino", entonces la "raza de los quechua y aymara" gozaba de una condición o status singular respecto de los habitantes de los llanos como los guaraníes, chiquitanos o mojeños. El "indio" del que hablaba Mendoza era, pues, el habitante de la montaña.

Por otro lado, en un intento por situarlo dentro del paraguas de la nación y, así, romper con la idea de una Bolivia blanca, Mendoza pareciera haberse visto obligado a legitimar y afirmar su rol fundamental en la historia del macizo, para lo cual insistió en la posibilidad de encauzar sus energías y reivindicó específicamente su valor funcional, esto es, su capacidad para aportar al engrandecimiento y evolución de la nación: el "indio" había sido y era un gran soldado, minero y obrero y, en el caso de la mujer, ella era la agente a través de la cual se transmitían las "admirables cualidades" que la altiplanicie había engendrado desde tiempos inmemoriales.

De esta manera, Jaime Mendoza contribuyó a forjar, en el intermedio del positivismo de Alcides Arguedas y el indigenismo romántico de Franz Tamayo ${ }^{14}$, una tradición de pensamiento nacional que se preguntó por las causas profundas de la inestabilidad boliviana y se propuso reflexionar sobre el llamado "problema indio", así como revisar el pasado con el propósito de regenerar la nación. Este escrito sostiene que ciertos elementos del planteo delineado por el pensador sucreño durante las primeras décadas del siglo XX pueden ser rastreados casi cien años después en el modo en que el MAS (re)presentó la memoria histórica de Bolivia en ocasión de la apertura del llamado "Bicentenario de los Pueblos". 


\section{El gobierno del MAS y la inauguración del "Bicentenario de los Pueblos"}

En el año 2009 Bolivia se convertía en el primer país de Sudamérica en inaugurar la ola de festejos bicentenarios que, por aquellos años, recorría la región. Sin embargo y contrariamente a lo que solía dictar la tradición, la conmemoración del bicentenario de la "Revolución de Chuquisaca" se halló dividida en dos: una en Sucre organizada por las autoridades locales -opositoras al MAS- donde se exaltaron a los hermanos Jaime y Manuel Zudáñez, Bernardo de Monteagudo y otros mestizos letrados de la Universidad San Francisco Xavier que participaron en la proclama del 25 de mayo de 1809; y la otra iniciada en Ravelo y finalizada en El Villar -dos poblados andinos a 56 km y 200 km de Sucre, respectivamenteprotagonizada por el gobierno central, quien adjudicó aquella decisión a los episodios violentos y racistas ocurridos en esta última en vísperas del aniversario patrio del $2008^{15}$.

El hecho de que el llamado "Bicentenario de los Pueblos 2009-2025" haya sido inaugurado en aquellas pequeñas localidades rurales del altiplano boliviano -en una de las cuales había funcionado el cuartel de operaciones de Juana Azurduy de Padilla en los dieciséis años que duró la guerra por la independencia- marcaría el tono del acto patrio organizado por el Poder Ejecutivo, el cual se propondría neutralizar el protagonismo de la ciudad y la participación criolla en la gesta independentista, rompiendo con la versión canonizada de la "Revolución de Chuquisaca" y exaltando la narrativa de "la Gran Rebelión Andina".

Vestido con trajes artesanales típicos de la región andina, el primer mandatario daría inicio a la celebración bicentenaria afirmando que se encontraba en Ravelo con el fin de

rendir homenaje a nuestros líderes, nuestros abuelos que lucharon por la independencia (...). Revisando nuestra historia, hermanas y hermanos, los grandes líderes de la liberación de nuestro país nacieron en la provincia de Chayanta en el norte de Potosí (...). Tomás Katari lidera el año 1770 los primeros levantamientos, los primeros cercos a la ciudad de La Plata (...) por las reivindicaciones del movimiento indígena, una lucha permanente por los derechos, la tierra, el territorio (...) 
Nuestros abuelos nos dejaron esa lucha (...) después de tantos años seguimos con nuestra música, con nuestra vestimenta (...) Tupaj Katari, ya del año 1780, grandes levantamientos, otros cercos en la ciudad de La Paz (...) Tomás Katari ha caminado a pie seiscientas leguas desde el norte de Potosí hasta Buenos Aires a plantear al virreinato (...) a defender la tierra (...) por nuestra cultura, por nuestra identidad (...) a hacerse reconocer como pueblos (ComunicaBolivia, 22 de mayo de 2009a)

En línea con la matriz interpretativa elaborada por Mendoza, vemos cómo para el presidente de Bolivia la guerra de independencia se había originado también en la altiplanicie andina, siendo conducida por un líder quechua y otro aymara, de los cuales -según postulaba Morales- descendían el actual movimiento indígena, así como sus demandas vinculadas a la lucha por las tierras y en estrecha relación con la defensa identitaria.

De igual modo, la preocupación histórica por la integración nacional, entendida como unidad territorial, que había llevado a Mendoza a afirmar que "las manifestaciones de predominio exagerado, las apetencias groseras, los cantonalismos ridículos, constituyen síntomas de desequilibrio pernicioso para los pueblos (...) hipertrofias que, a la larga, comprometen el juego normal de un organismo" (Mendoza, 2016, p. 109), ocuparía un lugar central en los discursos de Morales:

quienes piensan en dividir a Bolivia, quienes piensan en descuartizar a Tupaj Katari como lo hicieron antes, se equivocan, no podrán y por eso, nuestra tarea, hermanas y hermanos, es defender, junto a las fuerzas armadas, la unidad de nuestra querida patria Bolivia (...) siempre habían intentado, perdimos algunos pedazos de tierra pero ahora estamos (...) en tiempos de pueblo, en tiempos de una consciencia muy avanzada (...) en base a la igualdad (...) pero también por la unidad (ComunicaBolivia, 22 de mayo de 2009a)

Venimos aquí a rendir homenaje, no por miedo a algunos grupos de Sucre pero no queremos que sigan maltratándonos (...) como así expulsaron a un ser humano, un libertador (...) como José Antonio de Sucre expulsado por esos grupos oligárquicos... ese grupo todavía expulsa a nuestros constituyentes (...) la historia se repite (...) grupos de Sucre influidos por separatistas, terroristas desde Santa Cruz (...) que quieren dividir a Bolivia (ComunicaBolivia, 3 de junio de 2009a) 
En este sentido, la retirada a la periferia andina y la reformulación de la historia patria propuesta por el primer mandatario en ocasión del bicentenario de la "Revolución de Chuquisaca" pretendió constituirse en una afirmación andinista frente a los sectores autonomistas de la llamada Media Luna, especialmente, frente a las élites de Santa Cruz y la agrupación radical Nación Camba, las cuales-insistiendo en "que el Oriente de las tierras bajas es para los cruceños (blancos-mestizos) y elOccidente andino para los indios" (Plata, 2008, p. 102)- defendían las autonomías departamentales como respuesta al creciente poder indígena-popular y nacionalista (Gustafson, 2006) ${ }^{16}$.

De todos modos, este desplazamiento, a la vez, geográfico, simbólico y discursivo pareciera haber tenido otras connotaciones, esto es, cierto relego de las comunidades indígenas y campesinas de las tierras bajas del país -cada vez más numerosas debido a la creciente inmigración proveniente de las sierras ubicadas en Bolivia desde mediados del siglo XX (Mazurek, 2007)- como también de sus densos sectores urbanos.

Si bien el presidente destacaría que en Bolivia "los sectores más discriminados (...) son los quechuas, aymaras, los yucarés, los chiquitanos", insistiría que se encontraba allí para homenajear "a todos los líderes potosinos, chuquisaqueños, orureños, chapacos, cruceños, pandinos, paceños" y destacaría la importancia de que "los pueblos indígenas, originarios, obreros, patriotas de la clase media intelectual" llegaran "a ser gobierno" (ComunicaBolivia, 22 de mayo de 2009b), la centralidad otorgada a los Andes y a los pueblos aymara y quechua en su discurso dejaban en claro el lugar insoslayable que estos tenían en los orígenes y en la actualidad de Bolivia:

hermanas y hermanos, el primer grito libertario ha sido acá en el año 1770 a la cabeza de Tomás Katari, después viene Tupaj Katari, después viene Juana Azurduy, después viene Simón Bolívar a garantizar esa liberación de nuestros pueblos. (ComunicaBolivia, 22 de mayo de 2009a)

Es la fuerza del movimiento indígena de Abya Yala [que] se ha impuesto y saludamos a algunos mestizos así como a Juana Azurduy (...). Simón Bolívar así como tantos criollos, mestizos que se sumaron a esta lucha del movimiento indígena. Lamentablemente las verdaderas luchas desde 1500, desde 1600 no son reconocidas, ni recordadas, ni escritas desde el colonialismo, pasando por el imperialismo, el liberalismo y el neoliberalismo (ComunicaBolivia, 3 de junio de 2009a) 
Nuevamente, en sintonía con la argumentación trazada por Mendoza, Morales no dejaba lugar a dudas en cuanto a dónde había estallado la revolución y emergido la nación, ni en cuanto a quiénes habían sido sus auténticos precursores. Tanto el pensador sucreño como el primer mandatario entendían que solo siglos después de emprendida la lucha indígena en las montañas andinas, se sumarían a ella los mestizos y los criollos reivindicados en la narrativa liberal que persiguió la idea de una "nación sin indios", es decir, una Bolivia blanca y moderna".

Quien, en cambio, sería el encargado de introducir mayores matices al discurso pronunciado por Morales sería el vicepresidente del Estado Plurinacional, Álvaro García Linera, cuando en El Villar tomó la palabra para señalar que

Hace doscientos años, por estas montañas, por estos valles, por estos ríos de nuestra amada tierra cabalgaba la libertad de la mano de una mujer, de una madre heroína de todos los bolivianos y de toda América Latina. Esa chispa de hace doscientos años dio lugar a una (...) larga, cruenta guerra pero gloriosa guerra de emancipación de los bolivianos (...) por estas tierras cabalgó Juana Azurduy, una madre guerrillera, una madre comandante, una madre patriota que, espada en mano y caballo brioso iba liberando territorios no solamente de nuestra Chuquisaca sino que llegó a extenderse hasta llegar a Oruro, Potosí (...) Salta, Jujuy... por eso, el reconocimiento como una comandante de América Latina. Pero junto con ella, meses antes que ella, Zudáñez, Padilla. Y luego, después de ella, con ella, muchos otros patriotas, Muñecas en el norte de La Paz, Warnes en nuestra Santa Cruz, Esteban Arze en el valle, las madres heroicas cochabambinas (ComunicaBolivia, 3 de junio de 2009b)

Así, García Linera enaltecía el paisaje geográfico andino, "nuestra amada tierra", en la cual había nacido y luchado Azurduy, cuyo rol -combativo, pero también reproductivo- había sido esencial en la "gloriosa guerra de emancipación de los bolivianos". De igual modo, el vicepresidente enumeraba, nombraba y, por ende, incorporaba a la memoria histórica nacional a otros caudillos criollos y mestizos -incluidos Ildefonso de las Muñecas, sacerdote católico de La Paz, así como Ignacio Warnes, prócer de Santa $\mathrm{Cruz}^{18}$ para luego reanudar su relato afirmando que 
cuando en 1825 se funda la patria (...) los caudillos indios habían sido exterminados, los caudillos mestizos habían perecido (...) ¿quiénes quedaban? Los dos caras, los doctores dos caras, realistas opresores el día de ayer convertidos en un solo día en patriotas. La patria nació sobre el esfuerzo y la lucha de millones de indígenas y mestizos, de criollos, de la ciudad y el campo, pero que cuando culminaba su trabajo no estaban ellos para levantar con sus propias manos las nuevas instituciones. La victoria era del pueblo, la conducción era de los mismos de antes. Y por eso cuando nació Bolivia no... no se conquista la igualdad. Cuando nace nuestra patria habrán los ciudadanos con derechos políticos para gobernar y habrán el resto de bolivianos, sin derechos políticos, es decir, los indios, los trabajadores, los artesanos (ComunicaBolivia, 3 de junio de 2009b)

Por consiguiente, la formulación de García Linera adquiriría un tinte más abarcativo al remarcar la unión entre la participación indígena y el accionar mestizo y criollo -tanto femenino como masculino- y el elemento campesino con el urbano, postulando la idea de una independencia inconclusa debido al accionar de los "dos caras", el verdadero enemigo de la nación que se hizo del poder político a costa de la gesta popular.

En sintonía con esta perspectiva, la celebración del bicentenario de la Primera Junta Tuitiva de gobierno en julio de 2009 y, sobre todo, el $184^{\circ}$ aniversario de la independencia supondrían un leve giro respecto del modo en que el Poder Ejecutivo -y, puntualmente, el primer mandatario- había decidido reconstruir y representar la memoria histórica de la nación meses atrás, la cual -más allá de continuar girando sobre su eje, "la Gran Rebelión Andina"-admitiría cada vez más a otros actores y geografías de la nación.

Con una marcha de caballería que partió el lunes 13 de julio de 2009 desde El Villar con destino final a La Paz, comenzaba la celebración de los 200 años del grito libertario de julio de 1809. Sin embargo, no fue en la capital sino en una parada intermedia entre el punto de partida y llegada de la caravana, la localidad andina de Patacamaya, donde el primer mandatario y su equipo de gobierno inauguraron oficialmente la semana del bicentenario. Al hacer gala de la participación de mandatarios, en la que militares e indígenas de distintos países de América Latina se hicieron presentes en la velada, Morales exclamaría: 
Como siempre La Paz, demostrar que es el centro de integración no solamente de los bolivianos sino de todos los latinoamericanos. Y La Paz nuevamente debe de-mostrar, hermanas y hermanos, esa hermandad (...) esa amabilidad con los visitan-tes, esa hospitalidad, como siempre (...).

Yo siento que Sudamérica es una gran esperanza para todo el mundo (...) cuando los pueblos se organizan (...) se pueden resolver esas demandas, para algunos desde hace 500 años atrás, para algunos desde hace 200 años atrás y para todos los bolivianos demandas desde hace veinte años del neoliberalismo (...) estamos librando esa batalla (Comunica Bolivia, 13 de julio de 2009)

De este modo, en lo que puede ser entendido como una reformulación de la narrativa del país de contactos surgida en los treinta, Bolivia no solo sería en la actualidad parte de la nueva etapa de integración política y económica latinoamericana puesta en marcha hacia principios del 2000 -en rechazo a las medidas neoliberales del Consenso de Washington-, sino que la capital andina -por su centralidad geográfica en el subcontinente pero también por su carácter precursor en las luchas de independencia- debía encontrarse en el corazón del mencionado proyecto. Asimismo, Morales aprovecharía la ocasión para remarcar -en un claro guiño a los sucesos de Sucre- la "amabilidad" y "hospitalidad" de la capital andina, así como recordar que La Paz constituía el "centro de integración (...) de todos los bolivianos". A continuación, el primer mandatario volvería sobre el pasado para afirmar:

Tantos líderes que han dado su vida por nosotros y es nuestra obligación como hi-jos de Tupac Katari, como nietos y bisnietos de Bartolina Sisa, dar nuestro homena-je a esos hombres que dieron su vida, como Pedro Domingo Murillo, tantos en el Chaco, en Cochabamba, en Santa Cruz (...) civiles e indígenas (...) pero también militares (Comunica Bolivia, 13 de julio de 2009)

Establecida la importancia de La Paz, el presidente incorporaría referencias al oriente y sur del país -entre las cuales no estuvieron incluidas sus pretensiones separatistas- al tiempo que reivindicaría el carácter indígena, civil y militar de los líderes de la revolución. Por otro lado, cabe destacar la alusión a Pedro Domingo Murillo, quien, si bien formó parte de las tropas realistas que rompieron el cerco de La Paz en 1781, al tratarse del aniversario de la revolución paceña, su incorporación al altar de los héroes resultaba ineludible. 
Esta ampliación y flexibilización de la narrativa histórica trazada por el gobierno central se profundizaría con los discursos pronunciados el 6 de agosto de 2009 en Sucre. En efecto, Morales volvería a pisar la capital constitucional -luego de dos años de abierto conflicto y a cuatro meses de las elecciones presidenciales y parlamentarias ${ }^{19}$ para insistir en que "el mejor homenaje que podemos hacer hoy desde la Casa de la Libertad es respetando nuestras diferencias, respetando nuestros colores de partidos, [que] nos juntemos para servir mejor al pueblo boliviano"(Evo Morales citado en Vaca, 2009, párr. 13)

Igualmente, García Linera, al inaugurar la Sesión de Honor del Congreso Nacional en el marco del aniversario patrio en Sucre, aseveraría:

Hemos tenido enemigos de la patria internos y externos y lo seguiremos teniendo. Los tuvimos en 1825, en 1900, en 1960 y en 2008. Quiero que sepan que los hemos derrotado y los vamos a derrotar las veces que sea necesario. Una y otra vez porque la patria no se toca, no se divide, no se la mutila, no mientras estemos vivos nosotros.

(...) al egoísmo externo que roba la riqueza de la nación; a la ambición privada que quiere convertir el bien común en riqueza privada; al que privatiza los recursos del Estado y destruye las empresas públicas; y principalmente, al que por defender su hacienda, su empresa, su poder local o regional, es capaz de renunciar a la integridad de la patria (...). Si vuelven a levantar la cabeza, los volveremos a aplastar una y otra $v^{20} z^{20}$

El llamado a la unidad de la patria -protagonista de los discursos de agosto de 2009 se encontraba, al igual que para Mendoza a principios del siglo XX, estrechamente vinculado a la necesidad de proteger la tierra y garantizar su unidad ${ }^{21}$. Más allá de que las amenazas de los países vecinos ya habían cesado, el persistente peligro interno de los regionalismos y los nuevos desafíos provenientes del exterior ligados al neoliberalismo reactivaban el fantasma de la "mutilación" de la nación y su territorio. Por otro lado, vimos más arriba que el territorio boliviano y La Paz, en particular, debían reafirmarse en su calidad de centro de integración, pero también de resistencia frente a las amenazas que todavía pesaban sobre la nación y el subcontinente. 
Finalmente, cabe cerrar este apartado señalando que en esa importancia otorgada al territorio boliviano seguían conviviendo varias aristas que parecieran remontarnos a las obras de Mendoza. Así como para este último la altiplanicie constituía una fuente "de vida y energía" para la evolución de la nación y sus habitantes, García Linera exaltaba en El Villar la geografía andina que había sido cuna de los héroes y las heroínas de la independencia, así como Morales agradecía a "la madre tierra" por la oportunidad de "recordar las gestas libertarias de hacía doscientos años" (ComunicaBolivia, 15 de julio de 2009).

Ahora bien, y nuevamente en sintonía con la lente del pensador sucreño, esta mirada telúrica, antimoderna y comunitaria de la tierra -propia de la cosmovisión indígena de base andina- iba de la mano de una concepción estratégica y desarrollista de la misma. En efecto, Morales aseveraba en Sucre que

La colonización nos arrebató las tierras y nuestros antepasados lucharon para redistribuir estas tierras (...). Qué forma de pensar en la igualdad de todos los que habitan esta tierra. Tupac Katari decidió que nosotros debemos decidir el destino del país y no un grupo de extranjeros, es una forma de cómo nacionalizar instrumentos de opresión y humillación. Esa larga lucha por fin consiguió la liberación de esta tierra (Morales, 2009, párr. 5)

Con los recursos naturales de la nación boliviana y de las inversiones que el Estado hace en distintos rubros, como el minero, agropecuario, hidroeléctrico, los bolivianos mantenemos la esperanza de que seguirá cambiando la situación económica de Bolivia ${ }^{22}$

La gesta de Tupac Katari, al introducir la lucha por la tierra y posibilitar el arribo a horizontes poscoloniales, habría sentado las condiciones que ahora le permitían al gobierno del MAS -sucesor ideológico, así como espiritual de aquella lucharecuperar el control del suelo y gestionar-eficiente e igualitariamente, aunque no por ello pacíficamente- ${ }^{23}$ sus recursos naturales, con el propósito último de seguir aportando al desarrollo de la nación. 
Es así que, a lo largo del 2009, el MAS se asumió como la encarnación y realización de los valores, ideales y deseos de los levantamientos indígenas de finales del siglo XVIII. Una encarnación de carácter progresiva, lineal, superadora, pero "a la vez de regresión, de repetición y de renovación”. La “Gran rebelión andina” se convertía, entonces, en el elemento fundamental de una nueva memoria histórica y un rasgo central del intento gubernamental por alcanzar una mayor legitimación histórica y nacional.

\section{Conclusiones}

En El problema de la conciencia histórica Gadamer señalaba que esta "no oye más bellamente la voz que le viene del pasado, sino que, reflexionando sobre ella, la reemplazará en el contexto donde ha enraizado, para ver en ella el significado y el valor relativo que le conviene", denominando a este "comportamiento reflexivo cara a cara de la tradición” como “interpretación” (Gadamer, 1993).

En este sentido, la intención del MAS por reconstruir y representar la memoria histórica de la nación en clave popular, épica y libertaria lo llevaría a sumergirse en el pasado a fin de rastrear, restaurar y reinterpretar aquellas tradiciones de pensamiento nacional que le posibilitarían traer al presente el mito, la utopía y el valor de los pueblos indígenas, así como cuestionar los supuestos sobre los cuales se había sustentado a lo largo de dos siglos la identidad boliviana dominante.

Este trabajo entiende que -más allá de haber sido escasamente exploradas- las obras de Jaime Mendoza constituyeron uno de los insumos sobre los cuales se ancló el gobierno del MAS al momento de reelaborar el pasado y el presente nacional durante la inauguración del "Bicentenario de los Pueblos". En un país profundamente despojado y flagelado como Bolivia, la figura del "gran Macizo Andino" le había permitido a Mendoza encontrar un elemento de épica y fortaleza, cuya función política no era dividir al país sino precisamente evitar su desintegración al brindarle un núcleo fundamental capaz de mantener asida a la nación. Casi un siglo después, el MAS encontraba en los Andes un elemento mítico y poderoso para su retórica y práctica de reafirmación indígena y de confrontación con los sectores autonomistas y poderes imperiales que parecían amenazar la -históricamente esquiva- unidad nacional. 
Ahora bien, a diferencia de los viejos indigenismos como el esbozado por Mendoza, en el intento de reindianización encarado por el gobierno del MAS

la indianidad [irrumpiría] por abajo, como núcleo cohesionador de la identidad subalterna, de indígenas de carne y hueso (...) que cuestionan la inclusión abstracta y la exclusión concreta en la que aún se mantienen, en tanto siguen siendo, en gran medida, ciudadanos de segunda en su propio país (Stefanoni, 2010, p. 10)

Con todo, la naturaleza paradójica de aquella narrativa pareciera resultar inequívoca: si -como afirmaba el pensador sucreño- "Bolivia (...) es una sola montaña" (Mendoza, 2016), entonces, ¿qué significaba la búsqueda -previa y actual- por ampliar e integrar la nación? Tanto en Mendoza como en el gobierno del MAS aquel empeño había sido y seguía siendo esencialmente concebido en términos materiales -económicos e infraestructurales- $\mathrm{y}$, en ocasiones, la reivindicación indígena pretendidamente global- se había encontrado y continuaba encontrándose ceñida a lo quechua y aymara, perdiéndose de vista el resto de las identidades subalternas no andinas.

De modo que la reivindicación y reformulación del pensamiento de Mendoza por parte del gobierno del MAS pareciera -al menos hasta aquel entonces- haberlo condicionado frente al desafío histórico que este último -a pesar de todas las dificultades- se había propuesto enfrentar: zanjar la persistente fragmentación étnica y regional de Bolivia e intentar una auténtica construcción hegemónica a nivel nacional o, en otras palabras, una construcción transversal -a la vez, simbólica y material- de carácter plurinacional. 


\section{Notas}

${ }^{1}$ Un antecedente de este proyecto fue la Biblioteca del Sesquicentenario, creada en 1975 en el marco de la dictadura de Hugo Bánzer con el propósito de celebrar los 150 años de la independencia de Bolivia. Véase: http://www.la-razon.com/ opinion/columnistas/Biblioteca-Sesquicentenario_0_1713428740.html

${ }^{2}$ Esto, sostiene Bruslé (2015), se ve traducido en la geopolítica práctica a partir de diversas medidas gubernamentales como la implementación de corredores intercontinentales de conexiones, el aumento de las exportaciones de materias primas y la integración de Bolivia a prácticamente todas las alianzas regionales de Sudamérica.

${ }^{3}$ Si bien la lente se sitúa en las producciones discursivas del Poder Ejecutivo boliviano y se las piensa según su capacidad de modelar la realidad social, este escrito pretende asimismo inscribirlas en las fuerzas y determinaciones objetivas, en los comportamientos y gestos que, a la vez, limitaron e hicieron posible su enunciación. Porque creemos, siguiendo a Roger Chartier (2001), a contramano de los posicionamientos sostenidos por el llamado "giro lingüístico", que los discursos y las prácticas, la construcción discursiva del mundo social y la construcción social de los discursos constituyen dos esferas que, aunque relacionadas, pueden diferenciarse.

${ }^{4}$ Hacia finales del siglo XIX y principios del siglo XX, el determinismo geográfico -cuyas raíces se remontaban al mundo antiguo (Heródoto, Platón, Estrabón)entraba en contacto con las tesis evolutivas de Darwin y Spencer, desembocando en el positivismo naturalista o ambientalismo. Uno de sus mayores exponentes sería el geógrafo alemán Friedrich Ratzel, cuyos trabajos -embebidos de darwinismo social-suelen ubicarse en el origen de la Geopolítica. Puntualmente, la tesis central de la mencionada escuela geográfica afirma -partiendo de la aplicación del método empírico inductivo- que los fenómenos naturales y el medio ambiente poseen un 
papel determinante en la explicación de los procesos sociales, culturales y políticos (Fernández, 1987). Cabe agregar, en este sentido, la influencia económica, militar e intelectual que ejercía Alemania durante el primer tercio del siglo XX en Bolivia.

${ }^{5}$ Esta visión religiosa que sacraliza, legitima y da sentido al medio natural y sobrenatural andino, a la vez que supone una defensa de su identidad étnica, recorre especialmente la obra poética del autor, aunque, como veremos a lo largo de este apartado, aparece también en los dos escritos aquí recuperados.

6 Sin pretensiones de agotar el tema, el presente apartado se centra específicamente en el relato histórico trazado por Mendoza. En consecuencia, es preciso aclarar que muchas aristas de sus dos obras quedarán sin ser analizadas. Especialmente, los contenidos de El Macizo Boliviano, en tanto que la concepción histórica y sociogeográfica de la nacionalidad boliviana que me propongo rastrear se encuentra desarrollada con mayor profundidad en El factor geográfico en la nacionalidad boliviana; por su parte, El Macizo Boliviano, en cambio, consiste en una obra de divulgación que describe el paisaje geográfico del territorio boliviano en cuanto a potenciales viajeros.

${ }^{7}$ El proceso en cuestión, "a la vez de regresión, de repetición y de renovación”, involucraba a "Tihuanacu, Kollasuyo, Imperio Incaico, Audiencia de Charcas, Alto Perú, Bolivia: he ahí otros tantos momentos en el milenario palpitar del gran Macizo" (Mendoza, 2016, p. 288).

${ }^{8}$ Así como Mendoza dedicaba antes de morir un verso a la madre tierra denominado Pacha Mama (incluido en la reedición del 2016), en El Macizo... destinaba un apartado entero a la reflexión en torno al sol y al cóndor, además de realizar múltiples referencias a la luna.

${ }^{9}$ De hecho, más adelante el autor volvería a insistir sobre este asunto ratificando que "esas tierras, con ser lo importantes que son por sus productos propicios para la vida humana, no constituían, sin embargo, una parte esencial para la nación boliviana. Nosotros alguna vez las hemos calificado de ‘tierras de agregación'. Y en este sentido, estamos lejos de darles el mismo sentido que le damos al Macizo Boliviano. Ellas hasta podrían desaparecer en totalidad, sin que por eso muriese la nacionalidad" (Mendoza, 2016, p. 95). 
Esta argumentación tenía un fundamento científico: "Las tierras bajas circundantes por el norte, oriente y sudeste, no son sino rebalses aluvionales de dicho núcleo; este las ha hecho y sigue haciéndolas con las tierras que arrastran los ríos que desde el macizo des-cienden en esas direcciones. La montaña hace a la llanura y no la llanura a la montaña. Bolivia es, pues, ante todo, un país montañoso, una nación andina" (Mendoza, 2016, p. 286).

Por lo tanto, si bien prescindibles en lo relativo a su aporte a la nacionalidad y al Estado, lo que el autor sí reivindicaría era su valor material en la medida que allí existía, a diferencia del Macizo, un suelo rico en "productos propicios para la vida humana" y se encontraban "las grandes arterias fluviales que se dirigen al Amazonas y al Plata”, posibilitando al altiplano llegar al océano Atlántico. De modo que las tierras bajas del país eran, en la concepción de Mendoza, “elementos de vida y progreso", esto es, un medio para la grandeza económica y política del Macizo.

10 El autor se detiene a narrar los males que sacudieron a Bolivia desde su nacimiento que, por razones de espacio, no serán analizados en esta oportunidad. Es así que se refiere a los conflictos internos tras la independencia, la Guerra contra la Confederación Perú-Boliviana, la Guerra del Pacífico, la Guerra Federal, la Guerra del Acre y el tratado desfavorable con Chile en 1904 -a lo cual se sumaría después la Guerra del Chaco-, todos episodios que resultaron en la pérdida de la mitad de su territorio original.

${ }^{11}$ Cabe señalar que hacia principios de siglo XX “el Oriente liderizado por Santa Cruz, empieza a adquirir protagonismo, y el mapa regionalista que antes era longitudinal, se vuelve transversal” (Roca, 1997, p. 16). En ese marco y producto de las políticas económicas - principalmente, el tendido de las vías férreas- que significaban el predominio de La Paz y la consiguiente postergación de las tierras bajas, es que la élite política e intelectual cruceña comenzaría a organizarse frente al gobierno central.

En este sentido, se vuelve perfectamente coherente que Mendoza discutiera los relatos que caracterizaban a los cruceños como de origen hispano y provenientes de Asunción -lo que significaba a su vez que, entonces, eran parte de la región del Río de La Plata-, afirmando que "la ciudad de Santa Cruz, que parece escapar al núcleo orográfico, por hallarse en el comienzo de los llanos orientales, todavía 
le pertenece. Es todavía una ciudad andina" (Mendoza, 2016, p. 68). Del mismo modo, se comprende su insistencia en la necesidad de trazar "la gran línea de Santa Cruz que debe unir la Bolivia alta y la Bolivia baja” (Mendoza, 2016, p. 87).

12 Resulta difícil no asociar esta interpretación con el modo en que intelectuales como Ernesto Quesada y Luis Valcárcel, entre otros, se reapropiaban de la teoría de Spengler a fin de postular que, tras la "decadencia de Occidente", el nuevo impulso civilizador vendría de la mano del elemento indígena, el cual pondría fin a su estado de "barbecho" para invocar su propio destino (Bergel, 2006; Mailhe, 2016).

13 “¿Y qué decir de los resultados en los cruzamientos del indio y del blanco?", se preguntaba Mendoza, "En ellos, no podrá afirmarse que es el español quien ha triunfado. Es la raza subyugada, es la madre india quien supo trasmitir los principales caracteres de aquella en sus descendientes. Así se formó ese tipo humano -el mestizo- que hoy domina en Bolivia. Y así se vengó de la otra gran raza madre. Vencida en los campos de batalla, la venció en esos otros campos de las supremas luchas biológicas" (Mendoza, 2016, p. 112). Es interesante porque, sin adoptar una postura radical en torno al rol que debía desempeñar el "indio" en la nación, Mendoza se distanciaría de muchos teóricos del mestizaje como el propio Alcides Arguedas en Bolivia, al valorar positivamente los caracteres "indios" presentes en el mestizo, entendiéndolos como expresión del triunfo o imposición de esa raza sobre la española.

14 Cabe señalar que el ensayo Pueblo enfermo y la novela Raza de Bronce de Arguedas, así como las obras completas de Tamayo también fueron seleccionadas para ser publicadas entre los doscientos escritos emblemáticos de la cultura y la historia boliviana.

${ }^{15}$ Se refería a cuando grupos opositores impidieron la entrada del presidente a la ciudad luego de su rechazo a incorporar la demanda de capitalidad plena en la nueva Carta Magna, agrediendo a veintiocho campesinos, obligándolos a desnudarse en la plaza principal y repudiar al presidente. Esto, a su vez, tuvo otro antecedente: el 6 de agosto de 2007 Morales se vio obligado a abandonar la capital constitucional en medio de un ambiente hostil incitado por grupos opositores que abuchearon al mandatario exigiéndole que trasladara a Sucre los poderes del Estado que funcionan en La Paz. 
${ }^{16}$ Los fundamentos histórico-políticos de esta demanda serían tres: “el aislamiento geográfico de la región en el pasado; la marginación de las decisiones políticas de los destinos del país; y, contemporáneamente el avasallamiento o disputa de parte de los migrantes collas -en concomitancia con el Estado andinocentrista-, del territorio y los recursos naturales propios de los cruceños" (Plata, 2008, p. 104).

${ }^{17}$ El trabajo de Françoise Martínez (2013) exhibe cómo el repertorio de fiestas y celebraciones que se desarrollaron durante el primer siglo de vida republicana se constituyó en un mecanismo de integración y reconocimiento de la sociedad blancoide, anulando la cuestión de la integración indígena y mestiza a la imagen de la nación boliviana.

18 Resulta interesante esta particular mención porque Ignacio Warnes, militar porteño que fundó la "Republiqueta de Santa Cruz" -entonces adherida a las Provincias Unidas del Río de La Plata-, es una de las figuras más reivindicadas hasta el día de hoy por Nación Camba.

19 Cabe destacar que un año después Sucre se quedaría sin el monopolio del festejo de independencia. Es que, en el marco de esta búsqueda por dejar atrás los divisionismos, García Linera oficializaría en julio del 2010 que, a partir de entonces, la Asamblea Legislativa Plurinacional (APL) sesionaría cada 6 de agosto de manera rotativa para que las celebraciones llegaran a todo el país. Es así que ese año la APL sesionaría en Santa Cruz mientras que la parada militar sería en Cobija (Pando).

${ }^{20}$ Fragmento del discurso pronunciado en Sucre por Álvaro García Linera el día 6/8/2009. Disponible en: http:/www.jornadanet.com/Hemeroteca/n.php?a=35535$1 \& \mathrm{f}=20090807$

${ }^{21}$ Como señalaba Stefanoni: "desde el Occidente se teme que el objetivo de las demandas autonómicas se limite a controlar las tierras y los recursos naturales, fundamentalmente el gas y el petróleo" (Stefanoni, 2007, p. 63). 
${ }^{22}$ Fragmento del discurso pronunciado en Sucre por Evo Morales el 6/8/2009. Disponible en: http:/www.reporteconfidencial.info/noticia/6419/evo-moralesafirmo-que-bolivia-a-184-anos-de-su-independencia-seguira-su-crecimiento/

${ }^{23}$ De la cita se desprende también que, aunque el Estado plurinacional se ha propuesto como un ejemplo de "Buen Vivir" y contraglobalización, no pretende romper con las estructuras capitalistas ni prescindir de la explotación de recursos naturales en tanto la asume indispensable para su política social. Esto supone al gobierno una serie de contradicciones al continuarse con un modelo de desarrollo neoextractivo, el cual pondría en cuestión el alcance de las autonomías territoriales de los pueblos originarios establecidas en la nueva Constitución, provocando a su vez fuertes conflictos sociopolíticos con el movimiento indígena. 


\section{Referencias}

Bergel, M. (2006). Un caso de orientalismo invertido: la Revista de Oriente (1925-1926) y los modelos de relevo de la civilización occidental.

Prismas. Revista de Historia Intelectual, 1(10), 99-117.

Chartier, R. (2001). La historia, entre relato y conocimiento. Revista Historia y Espacio, (17), 185-206. Recuperado de http://bibliotecadigital.univalle. edu.co/bitstream/10893/7404/1/La\%20Historia\%20entre\%20relato\%20y \%20conocimiento\%20-\%20Chartier\%20Roger.pdf

ComunicaBolivia. (22 de mayo de 2009a). Evo Morales inicia actos en conmemoración del Bicentenario - Municipio de Ravelo - May 2009 1/2. [Archivo de video]. Recuperado de https://www.youtube.com/ watch?v=11S1tSSfEfw

ComunicaBolivia. (22 de mayo de 2009b). Evo Morales inicia actos en conmemoración del Bicentenario - Municipio de Ravelo - May 2009 2/2. [Archivo de video]. Recuperado de https://www.youtube.com/ watch? $=$ UXUWFqbg9a0

ComunicaBolivia. (3 de junio de 2009a). Bicentenario de los Pueblos en El Villar, Chuquisaca (1809-2009) 3/3. [Archivo de video]. Recuperado de https:// www.youtube.com/watch?v=n6arSuzaVn0

ComunicaBolivia. (3 de junio de 2009b). Bicentenario de los Pueblos en El Villar, Chuquisaca (1809-2009) 2/3. [Archivo de video]. Recuperado de https:// www.youtube.com/watch?v=khO6lqbNnYY

ComunicaBolivia. (13 de julio de 2009). Evo Morales encabeza marcha de caballería por el bicentenario de La Paz - julio 2009. [Archivo de video]. Recuperado de https://www.youtube.com/watch?v=ZGlm64C-NJ0 
Fernández, E. C. (1987). Notas sobre la evolución del pensamiento geográfico. Anales de geografía de la Universidad Complutense, 7, 43-52.

Funes, P. (2006). Salvar la nación. Intelectuales, cultura y política en los años veinte latinoamericanos. Buenos Aires, Argentina: Prometeo.

Gadamer, H. (1993). El problema de la conciencia histórica. Madrid, España: Editorial Tecnos.

Gustafson, B. (2006). Spectacles of autonomy and crisis: Or, what bulls and beauty queens have to do with regionalism in Eastern Bolivia. The Journal of Latin American and Caribbean Anthropology, 11(2), 351-379.

Mailhe, A. (2005). Epistemologías, oligarquías y escrituras en crisis. Del racialismo al culturalismo en el ensayo latinoamericano de los años treinta. Anuario de estudios americanos, 62(1), 29-53.

Mailhe, A. (2016). Polémicas ideológicas en la antropología argentina: el americanismo cientificista de la Biblioteca Humanior. En IX Jornadas de Sociología de la UNLP 5 al 7 de diciembre de 2016 Ensenada, Argentina. Universidad Nacional de La Plata. Facultad de Humanidades y Ciencias de la Educación. Departamento de Sociología. Recuperado de http://sedici.unlp.edu.ar/bitstream /handle/10915/61189/Documento completo.pdf-PDFA.pdf? sequence $=1$ \&isAllowed $=\mathrm{y}$

Martínez, F. (2013). Monumentos de papel. Las obras conmemorativas publicadas en México y Bolivia en el primer centenario de su independencia. Revista Boliviana de Investigación-Bolivian research review, 10, 47-90.

Mendoza, J. (2016). El Macizo Boliviano y El factor geográfico de la nacionalidad boliviana. La Paz: Biblioteca del Bicentenario de Bolivia. 
Mazurek, H. (2007). Three pre-concepts regarding the internal migration in Bolivia. Revista de Humanidades y Ciencias Sociales (Santa Cruz de la Sierra), 3, 1-15.

Morales, E. (2009). Declaraciones del Presidente de Bolivia en los actos por la celebración del bicentenario del grito libertario. Recuperado de http://www. cubadebate.cu/especiales/2009/07/16/declaraciones-del-presidente-debolivia-evo-morales-en-los-actos-por-la-celebracion-del-bicentenario-delgrito-libertario-video/\#.XRPdD1a72Um

Perrier Bruslé, L. (2015). La integración continental sudamericana, inscripción espacial y dispositivo discursivo. Apuntes desde Bolivia, el país de contactos. Journal of Latin American Geography, 14(2), 101-127.

Plata, W. (2008). El discurso autonomista de las élites de Santa Cruz. En X. Soruco (Cord.), Los barones del Oriente. El poder de Santa Cruz ayer y hoy (pp. 101-166). Santa Cruz: Fundación Tierra.

Stefanoni, P. (2007). Siete preguntas y siete respuestas sobre la Bolivia de Evo Morales. Nueva Sociedad, 209, 46-66.

Stefanoni, P. (2010). “Qué hacer con los indios...” Y otros traumas irresueltos de la colonialidad. La Paz, Bolivia: Plural editores.

Vaca, M. (2009). Morales regresa a Sucre dos años después. Recuperado de https:// www.bbc.com/mundo/america_latina/2009/08/090806_bolivia_morales_ sucre 